\title{
Bir Hassas Yaklaşma Prosedürü Olarak ILS'in (Instrument Landing System) Önemi ve Uçuş Gecikme Maliyetlerine Etkisi
}

\author{
Furkan $\mathrm{Kaba}^{1 *}$, Satilmiş Ürgün ${ }^{2}$ \\ 1 Kocaeli Üniversitesi, Fen Bilimleri Enstitüsü, Havacılık Bilimi ve Teknolojileri Bölümü, Kocaeli, Türkiye (ORCID: 0000-0003-3135-7507) \\ 2 Kocaeli Üniversitesi, Havacılık ve Uzay Bilimleri Fakültesi, Kocaeli, Türkiye (ORCID: 0000-0003-3889-6909) \\ (İlk Geliş Tarihi 21 Ocak 2019 ve Kabul Tarihi 2 Mart 2019)
}

(DOI: $10.31590 /$ ejosat.515682)

\begin{abstract}
ATIF/REFERENCE: Kaba, F., \& Ürgün, S. (2019). Bir Hassas Yaklaşma Prosedürü Olarak ILS'in (Instrument Landing System) Önemi ve Uçuş Gecikme Maliyetlerine Etkisi. Avrupa Bilim ve Teknoloji Dergisi, (15), 333-342.

$\ddot{O} \mathbf{z}$

Bir uçağın uygun doğrultuda ve süzülüş açısıyla inmesi için gereken veriler önemli ölçüde inilen havalimanında bulunan yaklaşma sisteminden temin edilmektedir. Hassas yaklaşma türleri içinde en yaygın kullanılan ILS (aletli yaklaşma sistemi, instrument landing system) oldukça önemli avantajlar sağlamaktadır. Bu çalışmada ILS'in çalışma prensipleri, kategorileri (CAT I/II/IIIa,b,c) ve bunların kullanım yerleri anlatılmıştır. Ayrıca seçilen örnek havalimanlarına dair veriler üzerinde yapılan hesaplamalar aracılığıyla, ILS kategorilerinin yükseltilmesinin önemini belirtilmiştir. Limit altı görüş nedeniyle yapılamayan veya geciken uçuşların sebep olduğu maliyetlere dikkat çekilmiştir.
\end{abstract}

Anahtar Kelimeler: Hassas yaklaşma, ILS, Gecikme maliyeti, Düşük görüş.

\section{The Importance of ILS (Instrument Landing System) as a Precision Approach Procedure and the Effect on the Delay Costs}

\begin{abstract}
The information needed to land with an appropriate bank angle and direction is provided by the current approaching system of the airport. ILS (instrument landing system) which is the most common precision approach procedure offers significant advantages. In this study, operational principles of ILS and the usage of the categories (CAT I/II/IIIa,b,c) have been mentioned. Besides that, the benefits of upgrading an ILS category were presented via low visibility percentage that has been calculated through the statistical data on the sampled airports. It was also pointed out the airline costs of delayed or canceled flight due to below the minimum.
\end{abstract}

Keywords: Precision approach, ILS, Delay cost, Low visibility

\footnotetext{
* Sorumlu Yazar: Kocaeli Üniversitesi, Fen Bilimleri Enstitüsü, Havacıllk Bilimi ve Teknolojileri Bölümü, Kocaeli, Türkiye, ORCID: 0000-0003-3135-7507, furkan-kaba@hotmail.com
} 


\section{Giriş}

Uçuş yüz yıllardır insanların hayali olmayı sürdürürken, 1871 yılında Alphonse Pénaud, ilk defa yapısal dengeli model uçağı 11 saniyede 40 metre uçurarak havacılıkta yeni bir çı̆̆ır açmıştır. Ardından yıllar sonra "Planophore" adını verdiği uçağın modellemesi Wright kardeşlerin ilham kaynağı olmuş ve 17 Aralık 1903 'te havalanan ilk uçakları havacılık tarihine damga vurmuştur.

Günümüzde ise havacılık teknolojileri her geçen gün gelişmekte ve havayolu taşımacılığı, ulaşım sektörünün hızla yükselen yıldızı olmaktadır. Uçağın güvenli şekilde uçuşu ve inişinde anahtar rol oynayan faktörlerden biri de kullanılan seyrüsefer ve yaklaşma sistemleridir. Yaklaşma, kabaca, uçağın belirli bir hat boyunca süzülerek havalimanına inişini tamamlaması süreci olarak tanımlanabilir. $\mathrm{Bu}$ süreçte uçağın ve pilotun güvenli yaklaşmayı gerçekleştirmesi için gereken bilgiler inilen havalimanında bulunan yaklaşma sisteminden temin edilmektedir. Yaklaşma sistemleri, farklı türdeki verileri referans alarak uçağın havalimanına olan mesafesi ve yaklaşma sırasında izlenmesi gereken süzülüş açısı, pistin coğrafi yönü gibi bilgileri uçağa gönderir.

Yaklaşma sistemleri, en temelde hassas ve hassas olmayan yaklaşma olmak üzere iki başlıkta incelenebilir. Hassas olmayan yaklaşma; yanal yönlendirmenin kullanıldığ fakat dikey yönlendirme bulunmayan bir aletli yaklaşma ve iniş sistemleridir (Annex 6). $\mathrm{Bu}$ yaklaşma sistemi VOR veya NDB gibi cihazlarla sağlanır. Bu cihazlar yer konuşlu olup radyo sinyalleriyle çalışan ve VFR uçuşlar dâhil olmak üzere, hava seyrüseferinde yol gösterme araçları olarak da kullanılırlar (Beköz ve Çakmaklı, 2014).

VOR (Very High Frequency Omnidirectional Range), VHF (Very High Frequency: 108,00 - 117,95 Mhz) yani çok yüksek frekans bandında, 360 derecenin her bir derecesinde kendi ekseni etrafında radyo sinyali gönderen bir yer vericisidir (Beköz ve Çakmaklı, 2014; THY, 2008). Uçağın VOR'a göre uçuşunun radyal cinsinden görünüşü Şekil 1.1'de görülmektedir.

NDB (Non Directional Beacon) ise, uçağın ADF'i tarafından alınan düşük frekanstan mors kodu ile birlikte yayın yapan radyo vericisi ve yön bulma aracı olarak tanımlanmaktadır (THY, 2008). Hassas olmayan yaklaşma sistemlerinde meydan minimumları yüksek olduğundan, düşük görüş ve düşük bulut tavanı şartlarında, ilgili meydanlara iniş yapılamamaktadır.

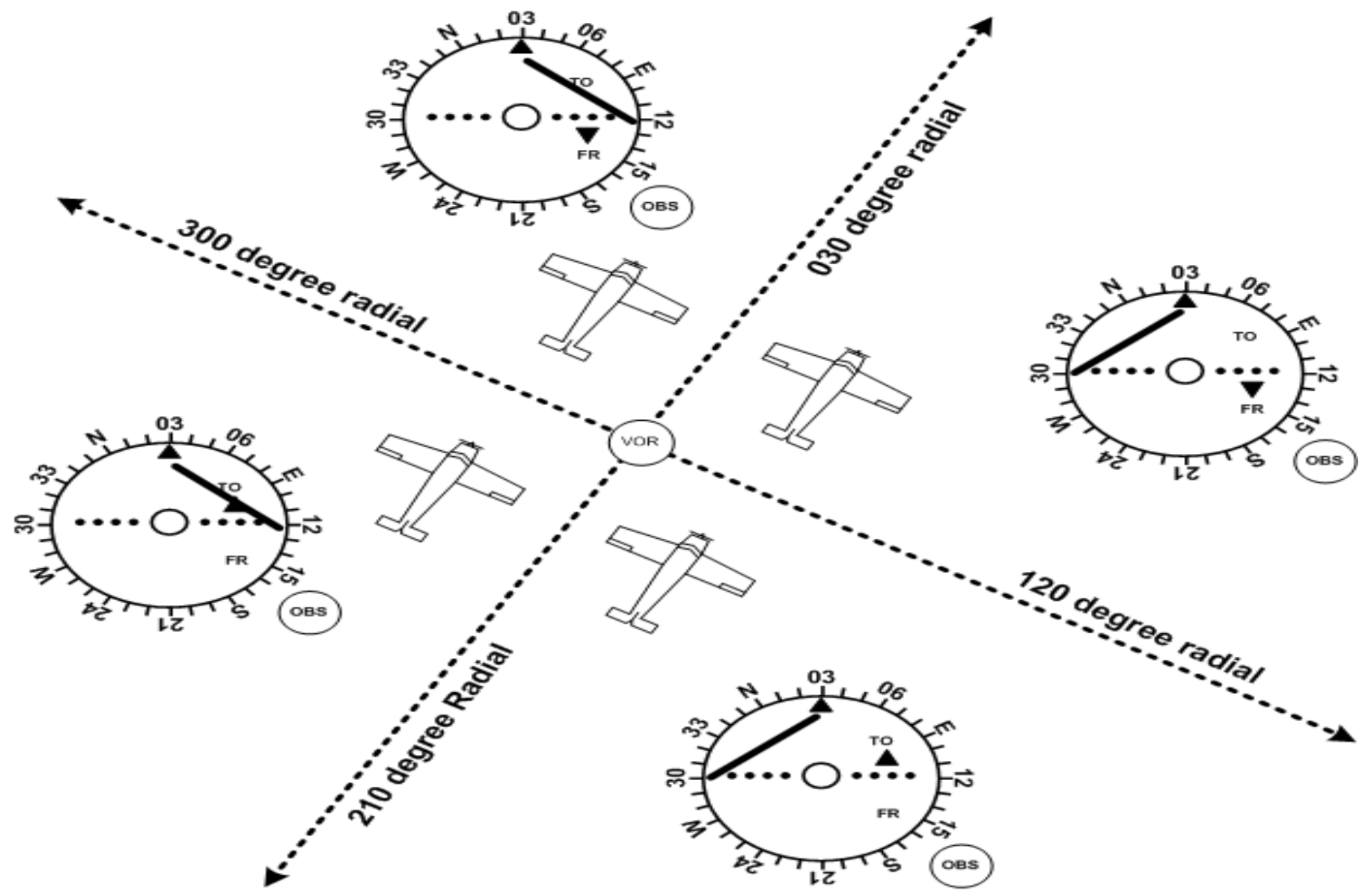

Şekil 1.1: Uçuş baş derecelerinin VOR'a göre görünüşü

(http://mattsflight.blogspot.com/2011/10/vor-navigation.html adresinden 06.01.2019 tarihinde alınmıştır.) 
Hassas yaklaşma; uçağın, operasyonel kategorilere göre yanal ve dikey bilgi sağlayarak yaptı̆̆ bir alet yaklaşması ve inişidir (Annex 6). Operasyonel Kategoriler, havalimanı yaklaşma prosedürlerine göre farklılık gösterip temelinde bulut tavanı ve görüs mesafesine göre sınıflandırılır. Pilot, ilgili havalimanındaki yaklaşma kategorisinin minimalarını kontrol edip, hali hazırdaki en güncel hava durumuyla kıyaslar ve iniş yapıp yapamayacağına bulut tavanı ve görüşe bağlı olarak karar verir. Mevcut operasyonel kategorilerde uygulanması gereken karar yükseklikleri ile pist görüş mesafelerine ait değerler Tablo 1,1'de gösterilmiştir (Annex 6 ).

Tablo 1.1: Operasyonel Kategoriler ile RVR ve DH değerleri.

\begin{tabular}{|c|l|l|l|}
\hline $\begin{array}{c}\text { Operasyon Kategorileri } \\
\text { (Karar Yüksekliği) }\end{array}$ & $\begin{array}{l}\text { RVR (Runway visual range- } \\
\text { Pist görüş mesafesi) }\end{array}$ & Görüş (Visibility) \\
\hline CAT I & $60 \mathrm{~m}$ ve üzeri $(>200 \mathrm{ft})$ & $550 \mathrm{~m}$ ve üzeri & minimum $800 \mathrm{~m}$ \\
\hline CAT II & $\begin{array}{l}30 \mathrm{~m} \text { ile } 60 \mathrm{~m} \text { aralığında } \\
(100 \mathrm{ft}-200 \mathrm{ft})\end{array}$ & $350 \mathrm{~m}$ ve üzeri & \\
\hline CAT IIIA & $\begin{array}{l}30 \mathrm{~m} \text { ve altı }(<100 \mathrm{ft}) \text { veya } \\
\text { DH olmadan }\end{array}$ & $200 \mathrm{~m}$ ve üzeri & \\
\hline CAT IIIB & $\begin{array}{l}15 \mathrm{~m} \text { ve altı }(<50 \mathrm{ft}) \text { veya } \\
\text { DH olmadan }\end{array}$ & $50 \mathrm{~m}-200 \mathrm{~m}$ aralı̆̆ında & \\
\hline CAT IIIC & DH olmadan & RVR limiti bulunmamakta & \\
\hline
\end{tabular}

Aletli hassas yaklaşma sistemi olan ILS (Instrument Landing System) uzun yıllardır kullanılmaktadır. ILS iniş sistemi, görüşün çok düşük olduğu şartlarda bile pilota ve uçağa referans sağlayarak güvenli bir şekilde inişe yardımcı olur bu nedenle günümüzde yaygın olarak kullanılmakta ve tercih edilmektedir. ILS alet alçalması sırasında, inilecek olan ilgili pist konfigürasyonu için dikey ve yatay olmak üzere bilgi vererek, hatasız şekilde yaklaşma ve inişi sağlar. ILS dört farklı bileşenden oluşmaktadır bunlar; Localizer, Glide Slope/Glide Path, Markerlar ve yaklaşma ışık sistemleri olarak adlandırılır. Localizer pist sonlarına yerleştirilen bir alet olup, yaklaşma hattı boyunca uçağa istikamet bilgisi verir ve yaklaşma esnasında yanal kaymayı önleyerek uçağın sabit bir hat boyunca yaklaşmasıını sağlar. Glide Slope ise gönderdiği sinyaller sayesinde, uçağın yaklaşık 3,0 derece açı ile pist başına doğru süzülüş yapmasını ve bu şekilde dikey olarak yaklaşma stabilitesinin oluşturulmasını sağlamaktadır. Bir ILS yaklaşması profili örneği Şekil 1.2 de görülmektedir.

$\mathrm{Bu}$ sistemde kullanılan bir diğer bileşen ise Markerlardır. Kendilerini tanıtmak amacıyla Localizer ve Glide-Slope/Path teçhizatlarının sinyallerinin belli mesafelerde dikine keserek yayın yaparlar. Alçalma yapan uçaklara pist başına olan mesafeleri hakkında bilgi verirler. Yaklaşma ş̧ıkları son yaklaşma esnasında, görsel olarak referans sağladığından ILS'in bir parçası olarak kullanırlar ve hassas yaklaşma olan pistlerde 720 metreden az olmamalıdırlar (Annex 14).

Havayolu taşımacılı̆̆ının sağladığı pek çok kolaylığın arka planında çok büyük bir organizasyonel alt yapı mevcuttur. Bu organize sistemdeki en ufak aksaklıklar bile ciddi maliyetler doğurmaktadır. Tam tersi, sistemin iyileştirilmesini sağlayacak küçük adımlar bile büyük ekonomik avantajlar getirebilmektedir. Düşük ILS kategorisine bağlı olarak birçok meydanda uçakların inişi gecikmekte veya o meydana iniş yapılamamaktadır. Havayolu taşımacılı̆̆ söz konusu olduğunda bir uçuşun gecikmesinden doğacak maliyetin hesaplaması oldukça karmaşık bir işlem olup ilk etapta akla gelmeyecek pek çok faktör bu maliyete etki etmektedir. Maliyet hesabı en temelde yakıt, uçağın bakımı, filo giderleri, personel maliyeti ve yolcu maliyetlerine dayanmaktadır. Bu parametrelerden doğan masraflar, uçağın uçuşun hangi aşamasında gecikme olduğuna göre de değişmektedir. Havadaki gecikme ile taksi sırasındaki veya pak pozisyonunda beklemenin maliyeti aynı olmamaktadır. Ayrıca gecikmeye konu olan uçağın tipi (B738, B744, A319, A321 gibi...) de bu maliyetleri etkilemektedir. Avrupa'daki havayollarını esas alarak gecikme maliyetleri için referans değerleri hesaplayan rapora göre 2014 yılı esas alındığında bir uçağın gecikme maliyeti dakika başına $100 €$ olarak belirlenmişsir. Bu rakam yukarıda sözü edilen tüm değişkenlerin yaklaşık değerlerine dayalı olarak hesaplanmıştır. Uçağın modeli vb faktörlere göre bu ortalama değer değişmekte olup, yakıt, bakım, personel veya yolcu giderlerinin bu değere yaptığı katkı da farklılaşmaktadır. Maliyetlerle ilgili daha detaylı bilgi için söz konusu çalışma incelenebilir (University of Westminster, 2015). 


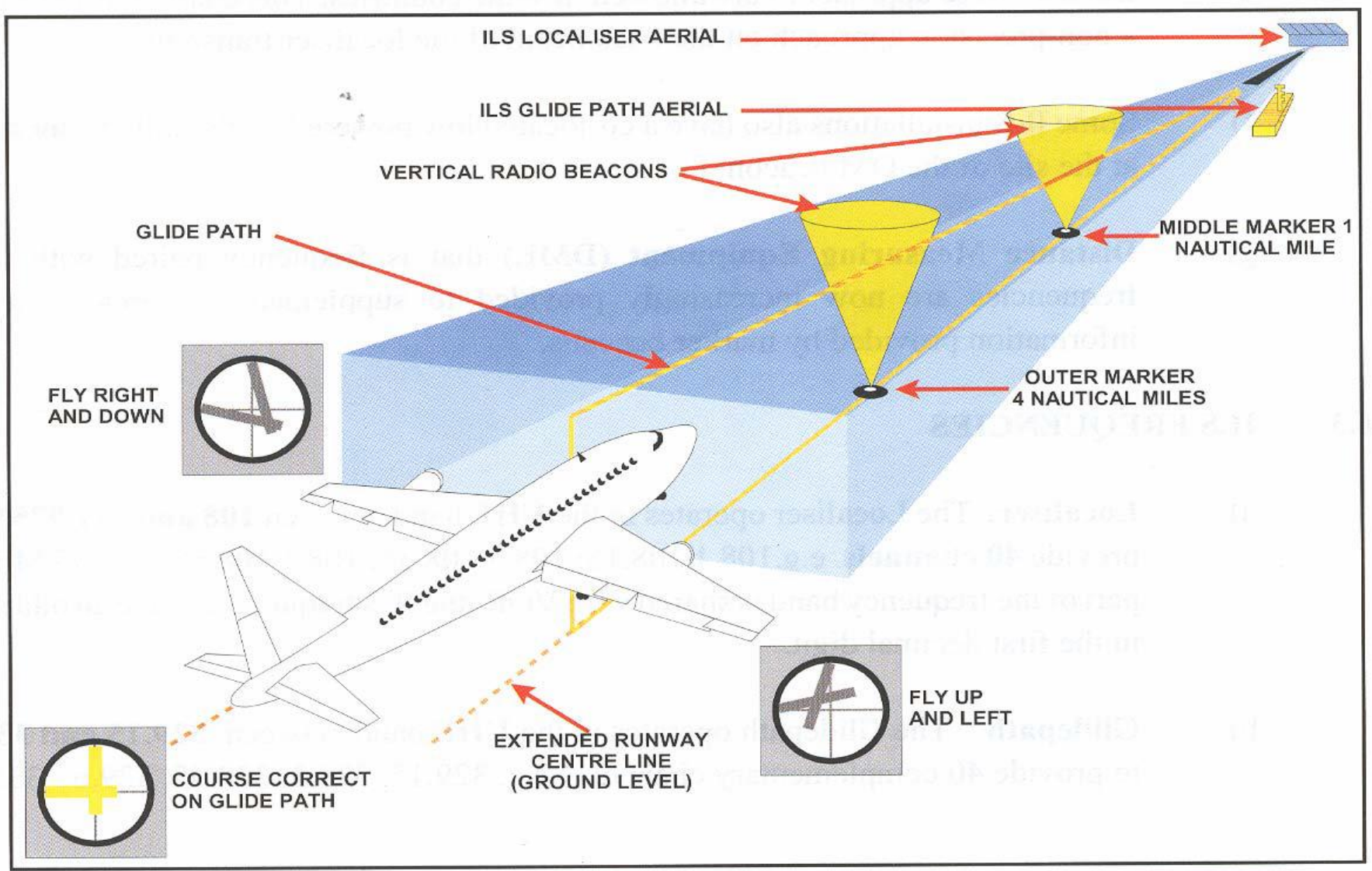

Şekil 1.2: ILS yaklaşma profili. (THY, 2008)

ILS sağladığı düşük görüş minimumları sayesinde, diğer yaklaşma türlerine kıyasla operasyonel açıdan çok daha uygun ve yararlı bir iniş destek sistemidir. Havalimanında ILS kurulumu belli (yeryüzü şekilleri, yükselti, doğal ve suni mânialar) şartlara bağlıdır. Bu şartlar yerine getirilip kurulum yapılabilirse, havayolu şirketlerinin uçuşlarını iptal etmeden, ya da gecikme yaşanmadan yapabilmesi daha fazla oranda mümkün olacaktır. Günümüzde artan yakıt, teknik bakım gibi maliyetler nedeniyle uçtuğu süre boyunca para kazanan uçaklar, uçmadıkları ya da gecikme yaşadıkları zamanlarda şirketlere ciddi mali kayıplar yüklemektedir. Buradan yola çıkan bu çalışmada, seçilmiş dört havalimanın mevcut ILS kategorisine bağlı olarak hava durumuna göre düşük görüş görülme oranları hesaplanmıştır. Düşük görüş, uçağın inişini geciktirecek veya inişi iptal ettirecek önemli bir faktör olup ILS kategorisi yükseltildiğinde bu gecikme veya iptallerden doğan yüksek maliyetlerin hangi oranda azalacağı ortaya konmak istenmiştir. Uygun koşullar sağlandığında ILS kategorisi değişikliğinin ne oranda fayda sağlayacağına dair tahmini bir değer sunulmuştur. Burada örnek verilen profiller için maliyet açısından sağlanacak avantaj kesin sayısal değerlerle ifade edilmemiştir. Bunun sebebi, hesaplamalar sonucunda elde edilen oranların ortalama değerleri vermesidir. Ayrıca bu veriler bir meydana iniş yapılamama oranı olup, o meydana yapılan seferlerin, seferleri yapmakta olan uçakların türünün ve bu seferleri düzenleyen havayolu şirketlerinin çeşitliliğine bağlı olarak ortaya çıkacak maliyet değişkenlik göstermektedir.

\section{Materyal ve Metot}

Bu çalışmada uluslararası hava durumu yayını yapan (Metar, Speci, Taf vb. ) veri tabanlarından alınan bilgiler kullanılmıştır. ILS kategorisi CATI ve CATII olan meydanlar seçilmiştir. Bunlar; Odesa (ODS), Bişkek (FRU), Priştine (PRN), Rostov (ROV) havalimanlarıdır. Bu havalimanları bölgesel olarak önemli yerlerde bulunup, coğrafi konumları ve hava durumlarından kaynaklanan düşük görüşlü zamanları sebebiyle sefer iptalleri ve bunun olası maliyetine dikkat çekmek için örnek olarak seçilmiştir. 2014'den 2019'a kadar (5 yıllık) Metar (rutin hava durumu verileri) ve Speci (rutin hava durumu meteorolojik parametrelerin, belirli kıstaslara göre değişmesi halinde yayınlanan veriler) verileri baz alınmıştır. Bu verilerin içinden de en çok limit dışı hava koşullarının görüldüğü Aralık, Ocak, Şubat ve Mart aylarının olduğu dönem seçilmiştir. Ardından bu aylarda, günlük ve saatlik olarak görüşün CATI minimumu olan 550 metrenin veya CATII minimumu olan 350 metrenin altına düşme riski yüzde (\%) olarak filtrelenmiştir. Odesa havalimanın ILS kategorisi CATI, diğer üç havalimanın ise CATII olup Priştine (PRN) ve Rostov (ROV) meydanlarının CATII kategorilerinin minimumu 300 metredir.

Daha önce belirtildiği üzere, görüş ILS CAT minimumu altına düştüğü durumlarda söz konusu meydanlara iniş yapılamamaktadır. Saatlik düşük görüş riski verisinden yola çıkılarak 24 saatlik yani bir günlük düşük görüş yüzdesi hesaplanmıştır. Bu oran, söz konusu meydana iniş yapılamama oranını yansıtmakta ve maliyet hesabı için referans bir değer sunmaktadır. Ayrıca her bir meydana ait günlük ortalama sefer sayısı, Eurocontol sistemi arşivinden alınarak maliyet hesabında kullanılabilecek bir diğer parametre olarak gösterilmiştir. 
Hava durumuna göre, uçağın ineceği havalimanında görüşün limit altına düşme oranına dair veri setinin bir örneği aşağıda görülmektedir. (Tablo 2.2) Bu tabloda Odesa havalimanında 2014-2019 yılları boyunca Ocak aylarındaki anlık hava durumu ve bunun limit altına düşme oranı gösterilmektedir. Gözlem sütunu, ilgili saat aralığında yayınlanan Metar ve Speci sayısını vermektedir. Gün sütunu, hava durumunun CATI minimumu olan 550 m'nin altına düşme sayısını, oran sütunu ise bu düşüşün yüzde cinsinden değerini belirtmektedir. Seçilen meydanlarda, seçilen yıllar ve aylar boyunca yapılmış saatlik gözlemler ve oranları veren istatistiki kayıtlardan yola çıkarak 4 örnek meydanın her birisi için ortalama düşük görüş görülme oranı hesaplanmıştır.

Tablo 2.2: Görüşün limit altına düşme oranı örnek veri seti

\begin{tabular}{|c|c|c|c|}
\hline \multicolumn{4}{|c|}{ ODESA(ODS) HAVALİMANI } \\
\hline 2014-2019 yılları & \multicolumn{3}{|c|}{ OCAK } \\
\hline Saat (Zulu Time) & Gözlem & Gün & Oran \% \\
\hline 00:00 & 154 & 21 & 13,6 \\
\hline 01:00 & 155 & 23 & 14,8 \\
\hline 02:00 & 155 & 23 & 14,8 \\
\hline 03:00 & 155 & 23 & 14,8 \\
\hline 04:00 & 154 & 23 & 14,9 \\
\hline 05:00 & 155 & 25 & 16,1 \\
\hline 06:00 & 156 & 21 & 13,5 \\
\hline 07:00 & 156 & 16 & 10,3 \\
\hline 08:00 & 156 & 15 & 9,6 \\
\hline 09:00 & 155 & 9 & 5,8 \\
\hline $10: 00$ & 155 & 10 & 6,5 \\
\hline $11: 00$ & 155 & 11 & 7,1 \\
\hline $12: 00$ & 155 & 7 & 4,5 \\
\hline $13: 00$ & 155 & 10 & 6,5 \\
\hline $14: 00$ & 153 & 9 & 5,9 \\
\hline $15: 00$ & 153 & 10 & 6,5 \\
\hline $16: 00$ & 153 & 11 & 7,2 \\
\hline $17: 00$ & 153 & 12 & 7,8 \\
\hline $18: 00$ & 153 & 14 & 9,2 \\
\hline $19: 00$ & 152 & 15 & 9,9 \\
\hline 20:00 & 152 & 18 & 11,8 \\
\hline $21: 00$ & 151 & 22 & 14,6 \\
\hline $22: 00$ & 153 & 18 & 11,8 \\
\hline $23: 00$ & 153 & 19 & 12,4 \\
\hline Saatlik & k görüş or & & 10,4 \\
\hline
\end{tabular}




\section{Araştırma Sonuçları ve Tartışma}

Tablo 2.2 örneği ve diğer istatistikî kayıtlarda yer alan verilerden yola çıkarak seçili aylara ait saatlik ortalama limit altı görüş görülme oranları seçilen havalimanlarını her biri için ayrı ayrı hesaplanmıştır. İlgili aya ait düşük görüş görülme oranı, o meydana yapılan seferlerin gecikme veya iptal olma oranı hakkında önemli bir ön bilgi sunmaktadır. Bu sebeple, her bir meydana ait aylık ortalama sefer sayıları da tablolarda verilmiştir. Buradan yola çıkarak, görüşün limit altı olma oranıyla paralel olarak, sefer sayılarının yapılamama/gecikme miktarı yaklaşık olarak tespit edilebilir ve tahmini zarar maliyeti veya riski hesaplamaları için bu oranlar kullanılabilir.

\section{1. Örnek Meydan 1: Odesa Havalimant}

Odesa Havalimanı için yayınlanan istatistikî verilerden yola çıkarak Ocak, Şubat, Mart ve Aralık aylarına ait ortalama sefer sayıları ve görüşün CATI minimumu olan 550 metrenin altına düşme oranı hesaplanmıştır. Buna göre söz konusu dört ay boyunca görüşün düşme oranı yaklaşık \% 9-10 civarında olup ilgili aylara göre çok fazla değişmemektedir. Bu oran havacılık sektöründeki özel koşullar göz önüne alındığında ciddi bir maliyet artış riskine işaret etmektedir. Yapılan hesaplamaların sonuçlarına ait sayısal verilerin özeti Tablo 3.1.1 ve Grafik 3.1.1'de görülmektedir.

Tablo 3.1.1: Günlük uçuş sayısı ve düşük görüş oranı

\begin{tabular}{|l|c|c|}
\hline ODESA HAVALIMANI & $\begin{array}{c}\text { GÜNLÜK ORTALAMA } \\
\text { SEFER SAYISI }\end{array}$ & $\begin{array}{c}\text { LIMIT ALTI OLMA ORANI } \\
(<\mathbf{5 5 0} \mathbf{~ m}) \%\end{array}$ \\
\hline OCAK & 15 & 10,4 \\
\hline ŞUBAT & 16 & 10,7 \\
\hline MART & 16 & 8,0 \\
\hline ARALIK & 20 & 8,8 \\
\hline
\end{tabular}

Grafik 3.1.1: Aylara göre düşük görüş oranları

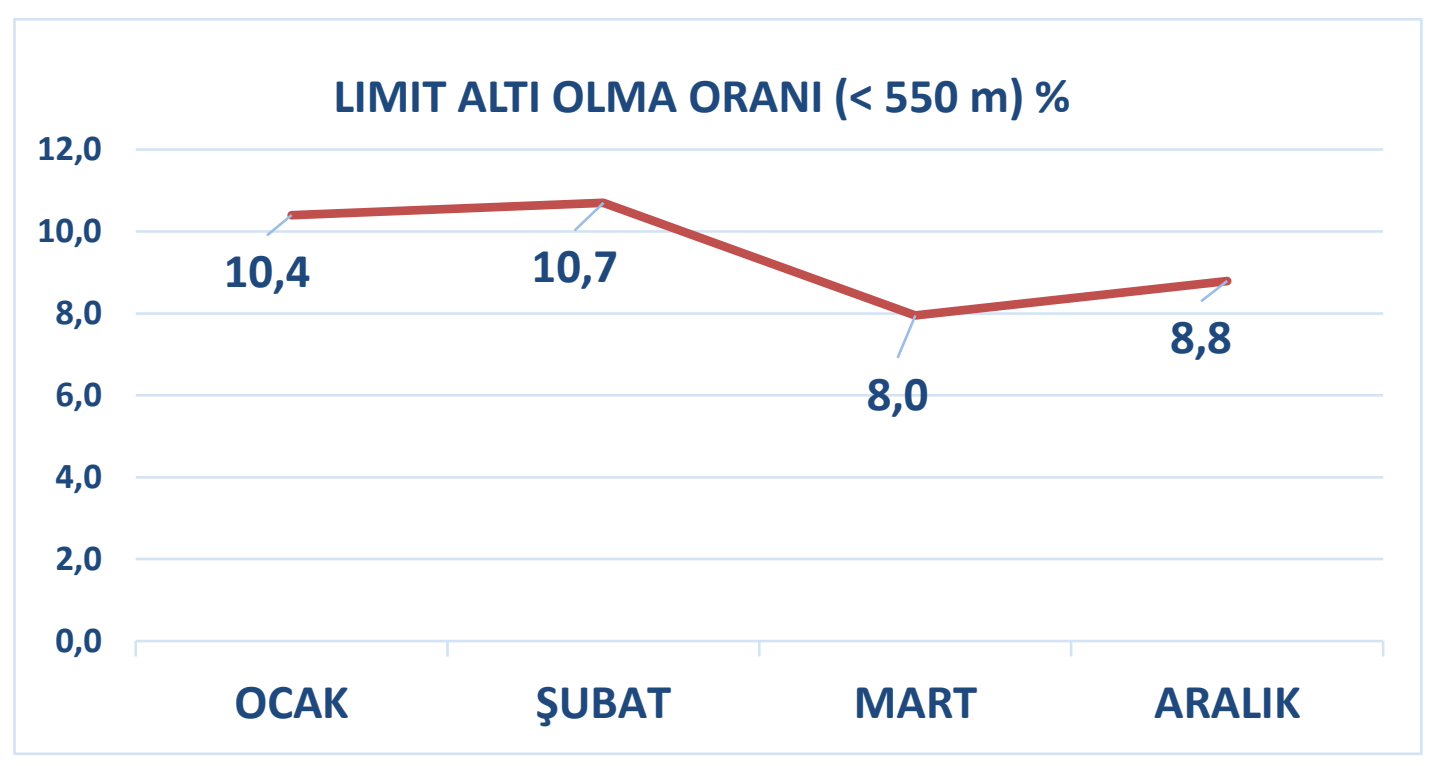




\section{2. Örnek Meydan 2: Bişkek Havalimanı}

Bişkek Havalimanı için yayınlanan verilerden yola çıkarak Ocak, Şubat, Mart ve Aralık aylarına ait ortalama sefer sayıları ve görüşün CATII minimumu olan 350 metrenin altına düşme oranı hesaplanmıştır. Buna göre söz konusu dört ay boyunca görüşün düşme oranı yaklaşık \% 4-5 civarında olup ilgili aylara göre çok fazla değişmemektedir. Bu oran ILS kurulumuna etki eden diğer faktörlerle beraber değerlendirilip kategori yükseltmenin maliyetlere nasıl yansıyacağı belirlenebilir. Yapılan hesaplamaların sonuçlarına ait sayısal verilerin özeti Tablo 3.2.1 ve Grafik 3.2.1'de görülmektedir.

Tablo 3.2.1: Günlük uçuş sayısı ve düşük görüş oranı

\begin{tabular}{|l|c|c|}
\hline BIŞKEK HAVALIMANI & $\begin{array}{c}\text { GÜNLÜK ORTALAMA } \\
\text { SEFER SAYISI }\end{array}$ & $\begin{array}{c}\text { LIMIT ALTI OLMA ORANI } \\
(<\mathbf{3 5 0} \mathbf{~ m}) \%\end{array}$ \\
\hline OCAK & 19 & 4,3 \\
\hline ŞUBAT & 17 & 6,5 \\
\hline MART & 18 & 1,3 \\
\hline ARALIK & 16 & 4,5 \\
\hline
\end{tabular}

Grafik 3.2.1: Aylara göre düşük görüş oranları

\section{LIMIT ALTI OLMA ORANI (<350 m) \%}

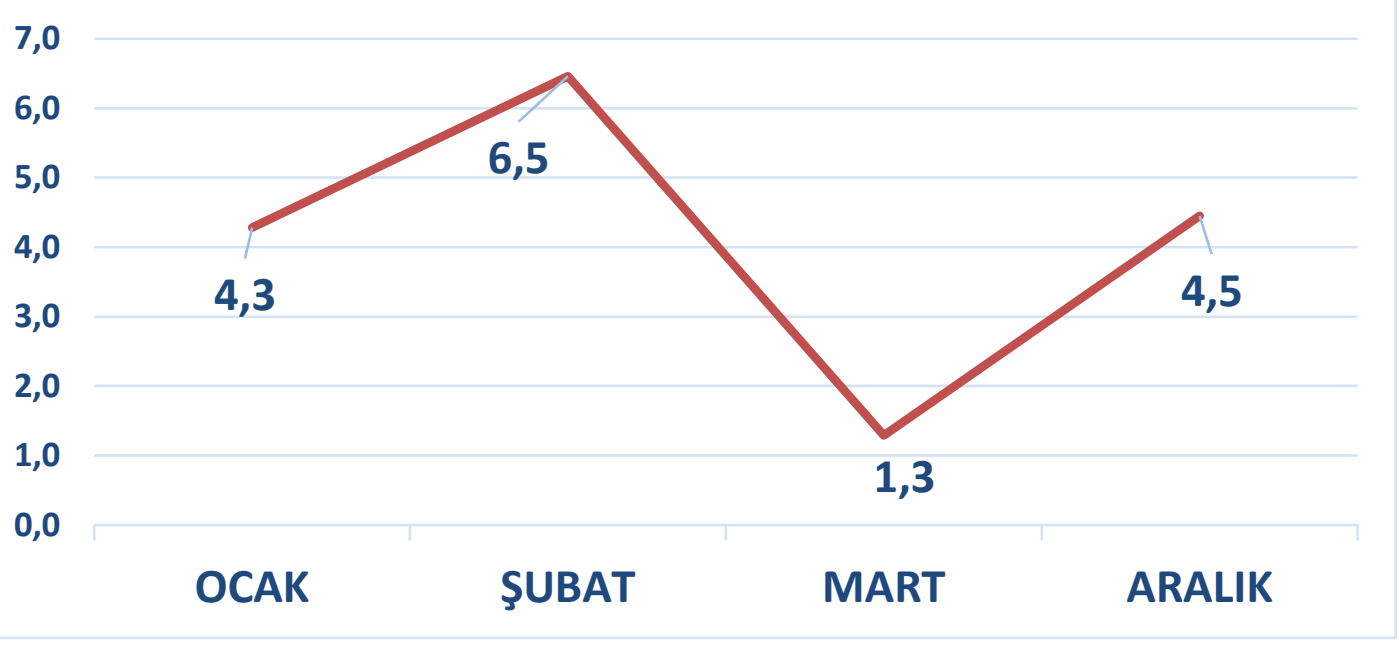




\section{3. Örnek Meydan 3: Priştine Havalimanı}

Priştine Havalimanı için yayınlanan istatistiksel verilerden yola çıkarak Ocak, Şubat, Mart ve Aralık aylarına ait ortalama sefer sayıları ve görüşün CATII minimumu olan 300 metrenin altına düşme oranı hesaplanmıştır. Buna göre söz konusu dört ay boyunca görüşün düşme oranı yaklaşık \% 4-5 civarında olmasına karşın, Ocak ve Aralık aylarındaki oran ise \% 8-9 olarak hesaplanmaktadır. Şubat ve Mart ayları için ihmal edilebilir görünen düşük görüş oranı Aralık ve Ocak aylarında ciddi bir maliyet artış riskine işaret etmektedir. Yapılan hesaplamaların sonuçlarına ait sayısal verilerin özeti Tablo 3.3.1 ve Grafik 3.3.1'de görülmektedir.

Tablo 3.3.1: Günlük uçuş sayısı ve düşük görüş oranı

\begin{tabular}{|l|c|c|}
\hline $\begin{array}{l}\text { PİRIŞTINE } \\
\text { HAVALIMANI }\end{array}$ & $\begin{array}{c}\text { GÜNLÜK ORTALAMA SEFER } \\
\text { SAYISI }\end{array}$ & $\begin{array}{c}\text { LIMIT ALTI OLMA ORANI } \\
(<\mathbf{3 0 0} \text { m) } \%\end{array}$ \\
\hline OCAK & 22 & 9,4 \\
\hline ŞUBAT & 20 & 1,0 \\
\hline MART & 20 & 0,4 \\
\hline ARALIK & 21 & 7,4 \\
\hline
\end{tabular}

Grafik 3.3.1: Aylara göre düşük görüş oranları

\section{LIMIT ALTI OLMA ORANI (<300 m) \%}
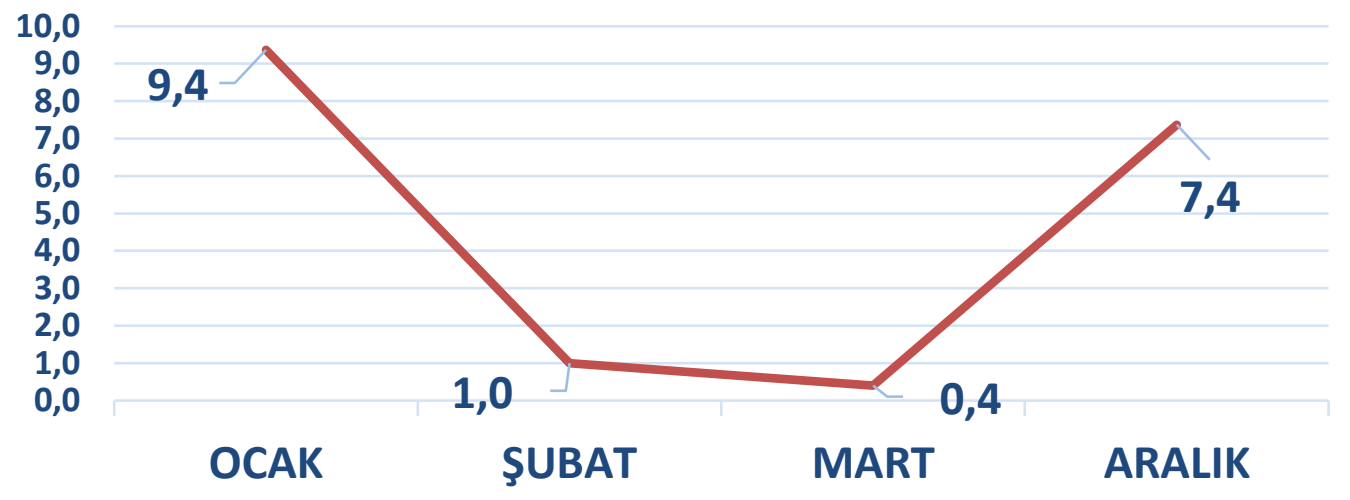


\section{4. Örnek Meydan 4: Rostov Havalimant}

Rostov Havalimanı için yayınlanan istatistikî verilerden yola çıkarak Ocak, Şubat, Mart ve Aralık aylarına ait ortalama sefer sayıları ve görüşün CATII minimumu olan 300 metrenin altına düşme oranı hesaplanmıştır. Buna göre söz konusu dört ay boyunca görüşün düşme oranı yaklaşık \% 8-9 civarında olup ilgili aylara göre çok fazla değişmemektedir. Mart ayı için ortaya çıkan oran düşük olsa da diğer üç ayın oranı havacılık sektöründeki özel koşullar araştırıldığında ciddi bir maliyet artış riskine işaret etmektedir. Yapılan hesaplamaların sonuçlarına ait sayısal verilerin özeti Tablo 3.4.1 ve Grafik 3.4.1'de görülmektedir.

Tablo 3.4.1: Günlük uçuş sayısı ve düşük görüş oranı

\begin{tabular}{|l|c|c|}
\hline $\begin{array}{l}\text { ROSTOV } \\
\text { HAVALIMANI }\end{array}$ & $\begin{array}{c}\text { GÜNLÜK ORTALAMA SEFER } \\
\text { SAYISI }\end{array}$ & $\begin{array}{c}\text { LIMIT ALTI OLMA ORANI } \\
(<300 \mathbf{m}) \%\end{array}$ \\
\hline OCAK & 27 & 8,4 \\
\hline ŞUBAT & 24 & 7,7 \\
\hline MART & 25 & 1,5 \\
\hline ARALIK & 24 & 10,2 \\
\hline
\end{tabular}

Grafik 3.4.1: Aylara göre düşük görüş oranları

12

$$
\text { LIMIT ALTI OLMA ORANI (<300 m) \% }
$$

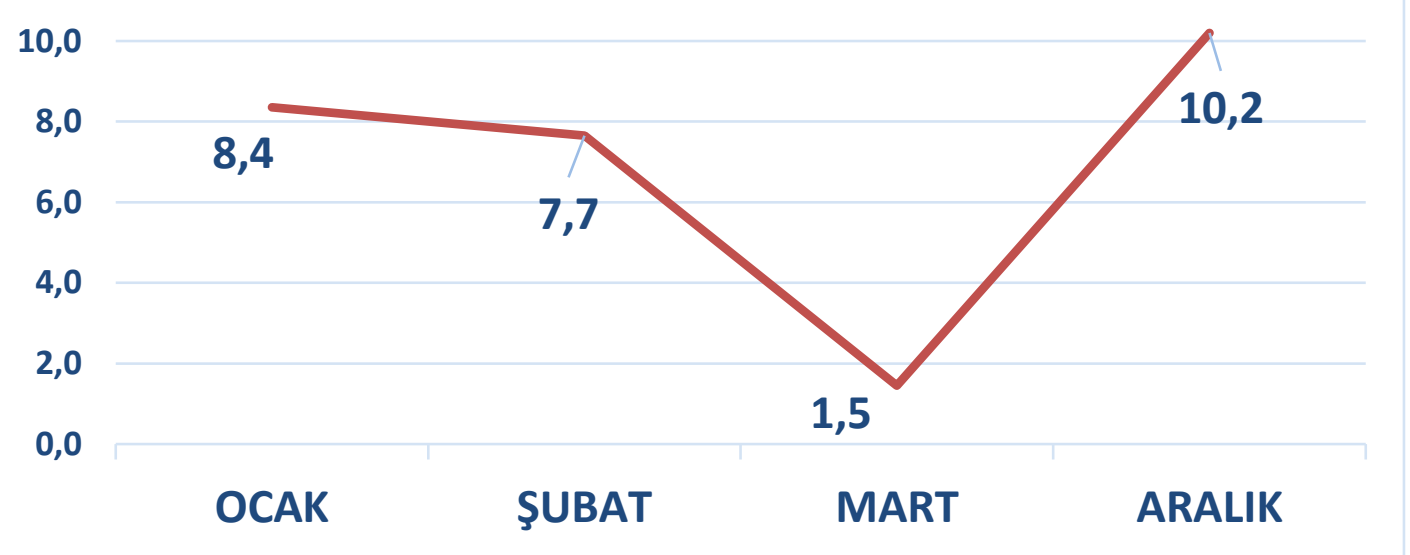

Herhangi bir havalimanına ILS (Instrument Landing System) uygulaması yapılmasını etkileyen birden çok etmen vardır. İlk olarak kurulumun yapılması planlanan havalimanının ICAO/Annex 14 de belirtilen şartlar doğrultusunda CATI, CATII ve CATIII a/b/c operasyonu için uygun olup olmadığı kontrol edilmelidir. Meydanın coğrafi konumuna bağlı olan hava durumunun karakteristik özelliklerini belirlemek amacıyla, uzun yıllar boyunca gerçekleşmiş görüş değerleri kontrol edilerek havalimanının operasyonel işletme kategorisi (CAT I/II/III/IIIa/IIIb/IIIIc) tespit edilmelidir. İlgili havalimanı için maniaların (doğal ve yapay yükseltiler) belirlenmesi ve bu yükseltilerin uygulanması planlanan operasyon kategorisi için uygun olup olmadığının teyit edilmesi ILS kurulumu için bir diğer önemli etmenlerden biridir. Maniaların uygun olduğu da teyit edildiğinde yaklaşma usulü oluşturulabilirse ILS teçhizatı istenilen kategoriye getirilebilir.

ILS cihazı çevresel faktörler ve arazi yapısına bağlı olarak çalışan bir teçhizat olduğundan Annex 10'da boyutları bulunan hassas bölgelere gerek duymaktadır. Bu sahaların yerleşim yeri yapılaşması veya sabit ve hareketli manialarla ihlal edilmemesi gerekmektedir. ILS cihazı bedeli ortalama 650.000 Amerikan doları civarındadır. Fakat kurulumun yapılacağı meydanın coğrafi yapısına göre kazı, dolgu gibi hafriyat maliyetleri değişecek olup bu da toplam maliyeti önemli ölçüde etkileyebilmektedir. 


\section{Sonuç}

Bu çalışmada ILS'in nitelikleri ve önemi anlatılmış olup ILS kategorisinin düşük olmasına bağlı olarak belirlenen zamanlarda uçuşlarda yaşanan gecikme/iptallerin oranı dört örnek meydan üzerinden ortaya konarak bunun maliyet üzerindeki etkisine dikkat çekilmiştir. Geçmiş beş yllı kapsayan istatistik verilerine dayalı olarak gerçekleştirilen hesaplamalar sonucunda \% 4-5’ten \% 10 seviyesine kadar ulaşan düşük görüş değerlerine bağlı olarak gerçekleştirilemeyen çok sayıda sefer bulunmaktadır. 2014 yılı Avrupa havayolları maliyet raporuna göre bir uçağın gecikme maliyetinin dakikada ortalama $100 €$ olduğu göz önüne alındığında düşük görüşe bağlı olarak gerçekleştirilemeyen seferlerin oldukça büyük maliyetlere yol açtığı söylenebilir. Üstelik bu maliyetler yalnızca havayolları için değil aynı zamanda meydan işletmeleri ve dolaylı olarak bu durumdan etkilenen diğer paydaşlar için de geçerlidir.

Öte yandan en yüksek kategori olan CAT IIIc sıfir görüşte bile iniş sağlıyor olsa da coğrafi, mali ve teknik kısıtlar yüzünden günümüzde az sayıda yerde kullanılmaktadır. Bu sebeple düşük kategorili tüm meydanlara CAT IIIb kurulumu yapılsa bile iniş riskleri veya iptal/gecikme maliyetler sıfira inmeyecektir. Bu çalışmada amaçlanan, düşük kategorili örnek meydanlardaki düşük görüşs oranını ortaya koyarak, geciken seferlerin miktarına ve bunların maliyetine dikkat çekmektir. Söz konusu meydanlar için ILS kurulumunu etkileyen diğer faktörler de göz önüne alınıp kurulumun maliyeti ile mevcut maliyetler karşılaştırılarak uygun koşullar tespit edildiğinde kurulumun yapılması makul olacaktır.

\section{Kaynakça}

Annex 6, (2010). International Civil Aviation Organization (ICAO).

Annex 10, (2001). Volume II, International Civil Aviation Organization (ICAO).

Annex 14, (2009). International Civil Aviation Organization (ICAO).

Beköz, Ü., ve Çakmaklı, S.S., (2014). Temel Uçuş Teorisi, 1.Baskı, Kaynak Ofset, İzmir.

European Airline Delay Cost Reference Values, (2015). University of Westminster,Version 4.1.

Radio Navigation, (2008). Oxford Aviation Academy (UK) Limited.

Radio Navigation, (2004). Jeppesen Sanderson Inc,.

Seyrüsefer, (2008). THY A. O., Uçuş Eğitim Akademi Müdürlüğü. 